\title{
Effects of Systolic Blood Pressure on Myocardial Infarction Patients
}

\author{
Rabindra Nath Das (Prof.) ${ }^{1,2^{*}}$, Youngjo Lee (Prof.) ${ }^{2}$ \\ ${ }^{I}$ Department of Statistics, the University of Burdwan, Burdwan, West Bengal, India \\ ${ }^{2}$ Department of Statistics, College of Natural Science, Seoul National University, Seoul, 151-747, Korea \\ *Corresponding Author: Rabindra Nath Das, Department of Statistics, The University of Burdwan, \\ Burdwan, West Bengal, India, E-mail: rabin.bwn@gmail.com
}

\section{INTRODUCTION}

High blood pressure (BP) is a primary cardiovascular risk factor. Both systolic BP (SBP) and diastolic BP (DBP) are defined by current guidelines [1-3]. Historically DBP has taken precedence in hypertension management. However, there are many strong evidences that SBP is superior to DBP as a cardiovascular events predictor $[4,5]$. Practically, hypertension (or elevated blood pressure) is positively connected with ischemic heart disease for $47 \%$, and $54 \%$ of stroke. It strongly affects approximately $30 \%$ of the adult population $[1,3$, 5]. Generally, cardiac factors such as SBP, DBP, ejection fraction, and heart rate are closely interconnected medical situations, and they coexist [3-5]. In practice, elevated BP is managed by pharmacotherapy. Practically, there are many risk factors such as family history, lifestyle, biochemical factors and sleep apnoea, which are associated with elevated BP [6, 7]. The following inquiries are searched in the current report.

- How do we determine the relationships of SBP with many other risk factors of acute myocardial infarction (AMI) heart patients?

- What are the associations of SBP with many other risk factors of AMI heart patients?

- What are the effects of SBP on other risk factors of AMI heart patients?

The above inquiries are searched herein with a real data set of 500 subjects on 18 factors/ variables from the Worcester Heart Attack Study (WHAS) that was investigated by Dr. Robert J. Goldberg, Department of Cardiology, and The University of Massachusetts Medical School. The data collection method and patient population are well described in [8], and the data can be found in Wiley's FTP site: $\mathrm{ftp} / / \mathrm{ftp}$.wiley.com/public/sci_tech_med/survival. For necessary use of the covariates, they are redisplayed as follows.

- $\operatorname{Sex}(0=$ male, $1=$ female $)$,

- Age at hospital admission,

- Initial heart rate (HR),

- Body mass index (BMI),

- Initial SBP,

- Initial DBP,

- History of cardiovascular disease (HCVD) $(0=$ no, $1=$ yes $)$,

- Congestive heart complications (CHC) $(0=$ no, 1 = yes),

- Atrial fibrillation (AFB) $(0=$ no, $1=$ yes $)$,

- Cardiogenic shock (CSK) $(0=$ no, $1=$ yes $)$,

- Complete heart block (AV3) $(0=$ no, $1=$ yes),

- MI type (MIT) $(0=$ non $\mathrm{Q}-$ wave, $1=\mathrm{Q}-$ wave),

- Myocardial infarction (MI) order (MIO) (0 = first, $1=$ recurrent),

- Cohort year (CYR) (1=1997, 2=1999, $3=2001$ ),

- Period of hospital stay from admission to discharge (PHS) (in days),

- Total follow-up days from hospital admission date to date of last follow-up (TFD)

- Discharge status from hospital (DSH) ( $0=$ alive, $1=$ dead $)$,

- Vital status at last follow-up (VSF) $(0=$ alive, $1=$ dead). 
The above data set contains seven continuous variables, and the rest are attributing. The above inquiries can be searched by modeling SBP on the remaining attribute/ variables. Note that SBP is a positive continuous non-constant variance random response which is non-normally distributed. Joint generalized linear models

Table1. Mean \& dispersion SBP models from joint Log-normal fit results

\begin{tabular}{|c|c|c|c|c|c|}
\hline Model & Covariate & Estimate & Standard error & t-value & P-value \\
\hline \multirow{10}{*}{$\begin{array}{l}\text { Mean } \\
\text { Model }\end{array}$} & Constant & 4.329 & 0.07441 & 58.173 & $<0.0001$ \\
\hline & Age & 0.002 & 0.00059 & 2.492 & 0.0131 \\
\hline & Sex & 0.047 & 0.01567 & 3.033 & 0.0022 \\
\hline & Heart rate (HR) & -0.001 & 0.00032 & -3.684 & 0.0001 \\
\hline & Diastolic BP (DBP) & 0.007 & 0.00036 & 19.885 & $<0.0001$ \\
\hline & Body mass index (BMI) & 0.002 & 0.00150 & 1.265 & 0.2081 \\
\hline & $\begin{array}{l}\text { History of Cardiovascular } \\
\text { Disease (HCVD) }\end{array}$ & 0.041 & 0.01611 & 2.544 & 0.0112 \\
\hline & Atrial Fibrillation (AFB) & -0.053 & 0.02069 & -2.566 & 0.0111 \\
\hline & Cardiogenic Shock (CSK) & -0.176 & 0.04565 & -3.864 & 0.0001 \\
\hline & MI Type (MIT) & -0.061 & 0.01676 & -3.655 & 0.0001 \\
\hline \multirow{6}{*}{$\begin{array}{l}\text { Dispersion } \\
\text { Model }\end{array}$} & Constant & -4.166 & 0.1608 & -25.907 & $<0.0001$ \\
\hline & $\begin{array}{l}\text { History of Cardiovascular } \\
\text { Disease (HCVD) }\end{array}$ & 0.482 & 0.1514 & 3.182 & 0.0021 \\
\hline & Cardiogenic Shock (CSK) & 0.468 & 0.3328 & 1.407 & 0.1602 \\
\hline & MI Order (MIO) & -0.205 & 0.1394 & -1.470 & 0.1422 \\
\hline & Cohort year (CYR)2 & 0.257 & 0.1584 & 1.619 & 0.1061 \\
\hline & Cohort year (CYR)3 & 0.526 & 0.1675 & 3.139 & 0.0022 \\
\hline
\end{tabular}

The data produced model fit should be tested by model diagnostic plots, which are presented in Figure1. Figure1 (a) presents the absolute residuals plot against the predicted SBP values, which is a flat straight line in the middle part, but its two ends are increasing as the larger observations are located at the two boundaries. It shows that variance is constant with the running means.

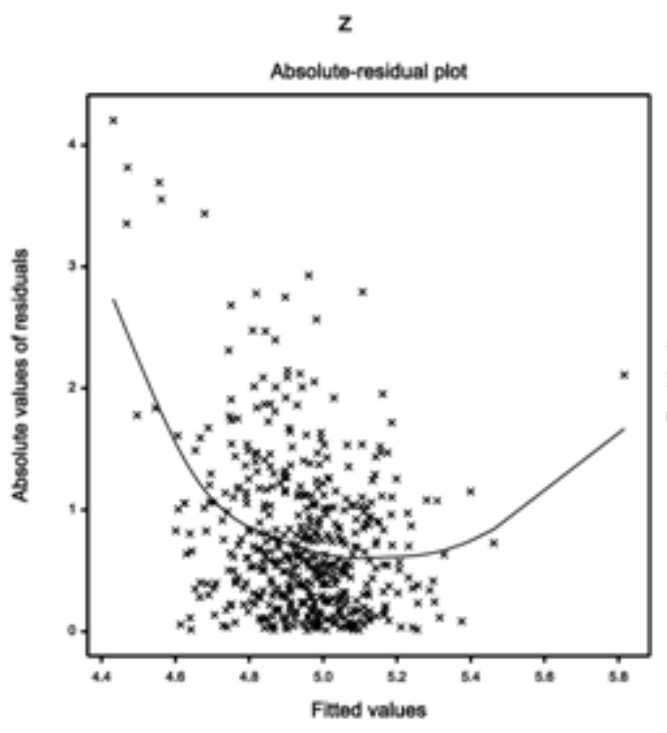

Figure 1(a)
(JGLMs) using Log-normal or Gamma distribution is an appropriate method for modeling SBP [9-11]. Here it is found that joint Log-normal fit of SBP gives better results than Gamma fit, and the final Log-normal JGLMs results are presented in Table 1.
Figure1 (b) shows the SBP normal probability plot for the Log-normal fitted mean model in Table 1, which does not reveal any lack of fit. Thus, both the plots show that Log-normal fitted SBP model (Table 1) is closely to its true models. Log-normal fitted SBP mean \& dispersion models are as follows.

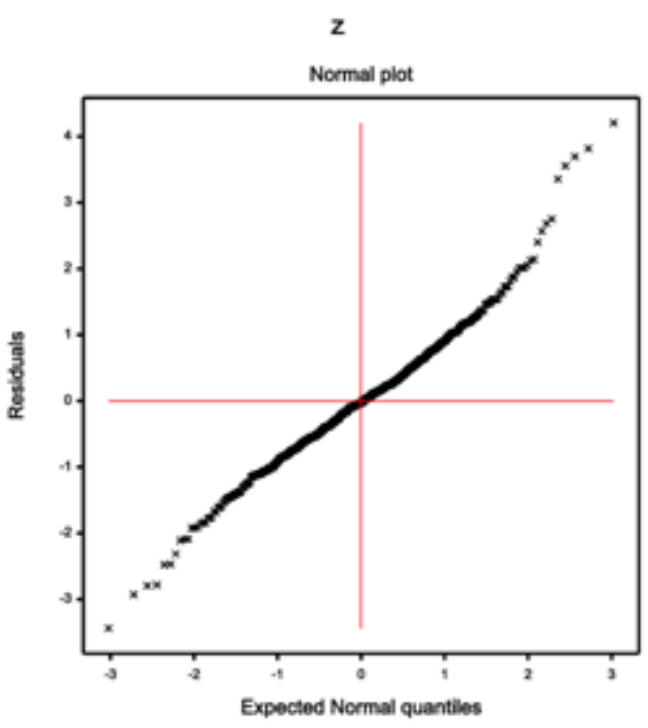

Figure 1(b)

Figure1. For the SBP Log-normal fitted models (Table 1) the (a) absolute residuals plot with respect to SBP fitted values, and (b) normal probability plot for the mean SBP model 
Mean $=\hat{Z}=\log (\mathrm{SBP})=4.329+0.002 \mathrm{Age}+$ $0.047 \mathrm{Sex}-0.001 \mathrm{HR}+0.007 \mathrm{DBP}+0.002 \mathrm{BMI}$ +0.041 HCVD $-0.053 \mathrm{AFB}-0.176 \mathrm{CSK}-$ $0.061 \mathrm{MIT}$,

Table 1 and the above SBP mean \& dispersion models show the following associations of SBP with other cardiac and biological factors.

- The mean SBP is positively associated with Age $(\mathrm{P}=0.0131)$, concluding that SBP is higher for older AMI patients than younger. For this data set, the mean age of AMI patients is 69.85 years with minimum age is 30 years.

- The mean SBP is positively associated with Sex $\quad(0=$ male, $\quad 1=$ female $) \quad(\mathrm{P}=0.0022)$, implying that SBP is higher for AMI female patients than male.

- The mean SBP is inversely associated with HR $(\mathrm{P}=0.0001)$, interpreting that it rises as HR decreases.

- The mean SBP is partially positively associated with BMI $(\mathrm{P}=0.2081)$, indicating that it is higher for obesity AMI patients than others.

- The mean SBP is positively associated with DBP $(\mathrm{P}<0.0001)$, concluding that it rises as DBP rises, which is commonly observed.

- The mean SBP is positively associated with history of cardiovascular disease (HCVD) $(0=$ no, $1=y e s)(P=0.0112)$, interpreting that SBP is higher for AMI patients with HCVD than others.

- The mean SBP is inversely associated with atrial fibrillation (AFB) ( $0=$ no, $1=y e s)$ $(\mathrm{P}=0.0111)$, implying that $\mathrm{SBP}$ is higher of AMI patients with no AFB than others.

- The mean SBP is inversely associated with cardiogenic shock (CSK) (0=no, 1=yes) ( $\mathrm{P}=0.0001)$, concluding that SBP is higher for AMI patients with no CSK than others.

- The mean SBP is inversely associated with MI type (MIT) (0=non Q-wave, 1= Q-wave) $(\mathrm{P}=0.0001)$, interpreting that SBP is higher for AMI patients with non Q-wave MIT than others.

- The variance of SBP is positively associated with HCVD ( $\mathrm{P}=0.0021)$, concluding that $\mathrm{SBP}$ variance is higher for AMI patients with HCVD than others.
Dispersion $=\hat{\sigma}^{2}=\exp (-4.166+0.482 \mathrm{HCVD}$

$+0.468 \mathrm{CSK}-0.205 \mathrm{MIO}+0.257(\mathrm{CYR}) 2+$ $0.526(\mathrm{CYR}) 3)$.

- The SBP variance is positively associated with cohort year (CYR) $(1=1997,2=1999$, $3=2001)$ at the year $3=2001,(P=0.0022)$, interpreting that SBP variance is higher for AMI patients at the cohort year $3=2001$, than the other years.

- The SBP variance is partially positively associated with cardiogenic shock (CSK) $(0=$ no, $1=$ yes $)(\mathrm{P}=0.1602)$, concluding that SBP variance is higher for AMI patients with CSK than others.

The report has shown some significant associations of SBP for AMI patients with some cardiac factors such as DBP, atrial fibrillation, HR, cardiogenic shock, history of cardiovascular disease, MI type, MI order, and along with age, BMI, sex, cohort year.

The effects of SBP on many cardiac factors are shown herein. Researchers and cardiologists will be benefitted from the report. For the AMI patients, special care should be taken on history of cardiovascular disease, SBP, DBP and HR.

\section{ACKNOWLEDGEMENT}

This research was supported by the National Research Foundation of Korea (NRF) grant funded by the Korea government (MSIT) (No. 2019R1A2C1002408).

\section{REFERENCES}

[1] Kearney PM, Whelton M, Reynolds K, Muntner P, Whelton PK, He J. Global burden of hypertension: analysis of worldwide data. Lancet 2005; 365:217--223.

[2] Benetos A, Thomas F, Bean KE, et al. Why cardiovascular mortality is higher in treated hypertensives versus subjects of the same age, in the general population. J Hypertens 2003, 21:1635-40.

[3] 3 Menni, C. Blood pressure pharmacogenomics :gazing into a misty crystal ball. J Hypertens 2015; 33:1142--1143.

[4] Falaschetti E, Chaudhury M, Mindell J, Poulter $\mathrm{N}$. Continued improvement in hypertension management in England: results from the Health Survey for England 2006. Hypertension 2009; 53:480--486.

[5] Parati G, Ochoa JE, Lombardi C, Bilo G. Assessment and management of blood pressure variability. Nat Rev Cardiol 2013; 10:143--155. 
[6] Stergiou GS, Bliziotis IA. Home blood pressure monitoring in the diagnosis and treatment of hypertension: a systematic review. Am J Hypertens 2011; 24:123--134.

[7] Krivokapich Janine, Child Jhon S., Walter Donald O. Garfinkel, Alan. Prognostic values of dobutamine stress echocardiography in predicting cardiac events in patients with known or suspected coronary artery disease. Journal of the American College of Cardiology 1999; 33(3):708--716.

[8] Hosmer, D.W. and Lemeshow, S. and May, S. Applied Survival Analysis: Regression Modeling of Time to Event Data: Second
Edition, John Wiley and Sons Inc., New York, 2008.

[9] Lee, Y, Nelder JA, PawitanY. Generalized Linear Models with Random Effects (Unified Analysis via $\mathrm{H}$-likelihood) (second edition). Chapman \& Hall, London 2017.

[10] Das RN and Lee Y. Log-normal versus gamma models for analyzing data from qualityimprovement experiments. Quality Engineering 2009; 21(1): 79-87.

[11] Lesperance ML, Park S. GLMs for the analysis of robust designs with dynamic characteristics. Jour. Qual. Tech., 2003; 35:253-263.

Citation: Rabindra Nath Das, Youngjo Lee, Effects of Systolic Blood Pressure on Myocardial Infarction Patients). ARC Journal of Cardiology. 2019; 5(2): 10-13. doi:dx.doi.org/ 10.20431/2455-5991.0502002.

Copyright: (C) 2019 Authors. This is an open-access article distributed under the terms of the Creative Commons Attribution License, which permits unrestricted use, distribution, and reproduction in any medium, provided the original author and source are credited. 